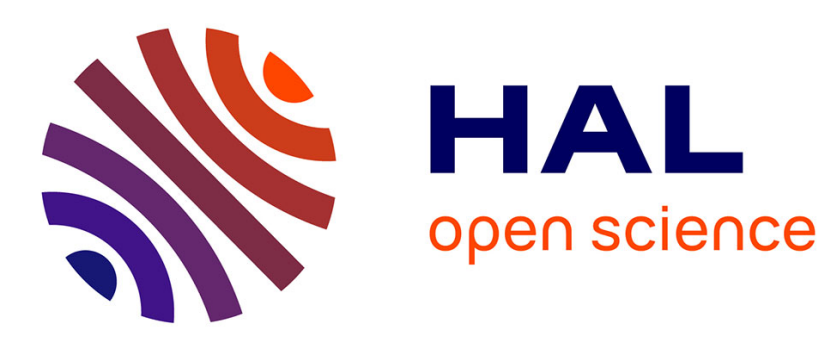

\title{
Gypsum and spalling decay mechanism of Tuffeau limestone
}

\author{
Sarah Janvier-Badosa, Kévin Beck, Xavier Brunetaud, Audrey \\ Guirimand-Dufour, Muzahim Al-Mukhtar
}

\section{To cite this version:}

Sarah Janvier-Badosa, Kévin Beck, Xavier Brunetaud, Audrey Guirimand-Dufour, Muzahim AlMukhtar. Gypsum and spalling decay mechanism of Tuffeau limestone. Environmental Earth Sciences, 2015, 74 (3), pp.2209-2221. 10.1007/s12665-015-4212-2 . hal-02090620

\section{HAL Id: hal-02090620 \\ https://hal.univ-lorraine.fr/hal-02090620}

Submitted on 4 Apr 2019

HAL is a multi-disciplinary open access archive for the deposit and dissemination of scientific research documents, whether they are published or not. The documents may come from teaching and research institutions in France or abroad, or from public or private research centers.
L'archive ouverte pluridisciplinaire HAL, est destinée au dépôt et à la diffusion de documents scientifiques de niveau recherche, publiés ou non, émanant des établissements d'enseignement et de recherche français ou étrangers, des laboratoires publics ou privés. 


\title{
Gypsum and spalling decay mechanism of Tuffeau limestone
}

\author{
Sarah Janvier-Badosa ${ }^{1}$, Kévin Beck ${ }^{1}$, Xavier Brunetaud ${ }^{1}$, Audrey Guirimand-Dufour ${ }^{2}$, Muzahim Al-Mukhtar ${ }^{1}$ \\ ${ }^{1}$ Univ. Orléans, INSA-CVL, PRISME - UPRES EA 4229, 8 rue Léonard de Vinci, F-45072, Orléans, France \\ 2Univ. Orléans, CETRAHE (CEllule R\&D d'Expertise et de TRAnsfert en TRAcages Appliqués à l'Hydrogéologie et à \\ I’Environnement), 8 rue Léonard de Vinci, F-45072 Orléans, France
}

\begin{abstract}
:
The general form of degradation of tuffeau is the progressive spalling of the surface of the stone. Over time, thick plates (one- to three-centimetres thick) form gradually on the surface of the stone. Once the plate drops, the resulting stone surface turns into powder. At the Castle of Chambord, mineralogical analysis of the degraded stone, throughout its depth, shows the presence of gypsum $\left(\mathrm{CaSO}_{4} .2 \mathrm{H}_{2} \mathrm{O}\right)$ located mainly within a crack network parallel to the surface. The objective of this research is to study different hypotheses of gypsum formation to improve the understanding of the damaging process of spalling.
\end{abstract}

Fresh stones were subjected to artificial ageing in the laboratory through imbibition/drying tests, to study the resulting distribution of gypsum as a function of several parameters: the source of gypsum, initial stone cracking, drying conditions, and analysis after different measurement sequences. Tested samples were analysed at different stages of ageing by using $\mathrm{X}$-ray diffraction and ion chromatography to localise and quantify the amount of gypsum throughout the depth. Results indicate that gaseous $\mathrm{SO}_{2}$ can lead to a distribution of gypsum very similar to that observed in stones subjected to spalling in situ at the Castle of Chambord.

Keywords: Limestone tuffeau, spalling, gypsum, artificial ageing, mechanism of degradation

\section{Introduction}

White tuffeau is a stone commonly used as a building material, for example, in the construction of the Castle of Chambord, as well as most of the built cultural heritage of the Loire Valley, France. This stone is a soft, porous and very fine grained siliceous limestone with a small amount of clayey minerals, and the most widespread and damaging form of stone degradation is spalling (Beck et al. 2003; Beck and Al-Mukhtar 2005). Over time, thick plates one- to threecentimetres thick gradually form on the surface of the stone. The plate eventually drops and the resulting stone surface turns into powder (Fig. 1). Typically, this degradation affects vertical walls and it is often initiated at the corners of pilasters, the framing of windows and stonework joints (Jeannette 1992). Spalling is not associated with the orientation of the stone on the building: examples were observed in any direction in space, and on higher or lower parts of the façade. It is a very destructive degradation and, for example, in the east tower of the castle of Chambord, it affects around $5 \%$ of the walls (Janvier-Badosa et al. 2013a). 

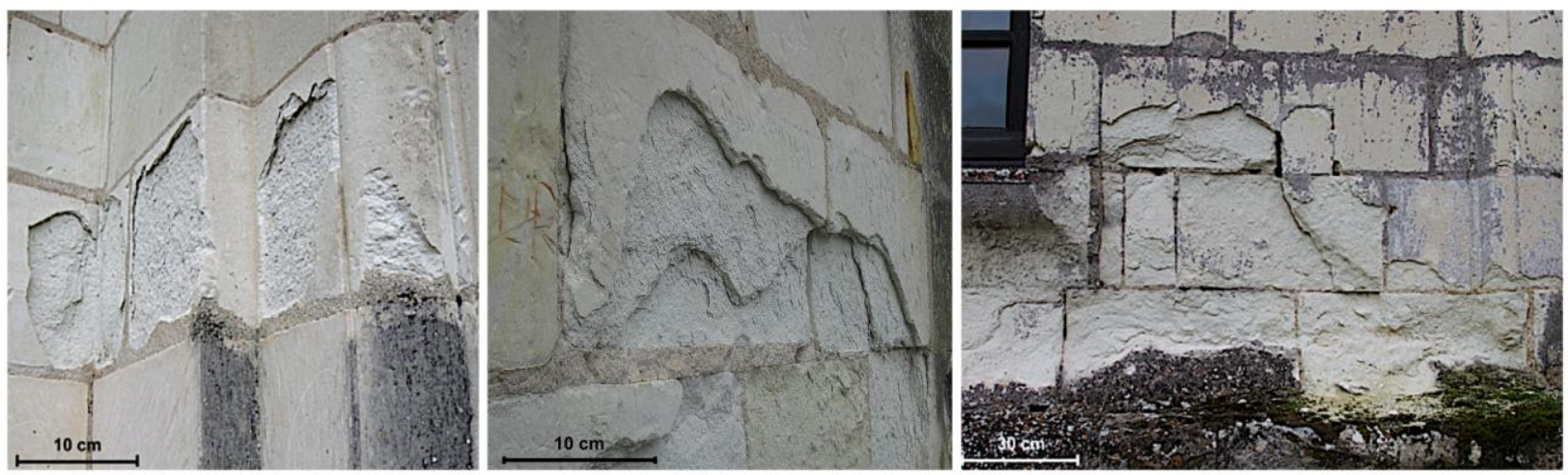

Figure 1. Examples of stone spalling at the Castle of Chambord

In the current state of knowledge concerning tuffeau spalling, it is not yet possible to determine the parameters governing the formation of the plaque, because no proposed hypothesis has ever been validated experimentally. Rautureau (2001) and Brunet-Imbault (1999) stated that the dissolution of calcite from the stone and its subsequent crystallisation at the surface would generate a hardened and waterproofed layer promoting water movement parallel to the surface, thus increasing the local dissolution of calcite and the weakening of the stone matrix. Berthonneau et al. (2012), Gutiérrez et al. (2012), Colas et al. (2011) and Benavente et al. (2008) argued that the daily thermal and hydraulic cycles generate restrained differential dilations between the core and the surface, which would initiate and propagate microcracks in the stone, specifically in the presence of potentially swelling clay minerals. Finally, Jeannette (1992) and Cautru (1976) claimed that gypsum could crystallise and accumulate in the drawdown area of water movements, generating heterogeneities in the stone's physical properties with the local crystallisation pressure leading to progressive stone cracking. This latter hypothesis is supported by recent analyses on samples cored from different parts of the Castle of Chambord subjected to spalling, revealing that the content of gypsum is found systematically to be around $1.5 \%$ in weight (Janvier-Badosa et al. 2013b). This content is found to increase from the surface to the first crack at a depth of approximately $1 \mathrm{~cm}$ and then it decreases progressively with depth. Moreover, other samples, cored in stones without apparent damage, showed the presence of gypsum at $1 \mathrm{~cm}$ depth in areas that were direct extensions of cracks.

Different sources of gypsum can be considered to explain the systematic presence of gypsum in stones that have been subjected to spalling: atmospheric pollution due to industry and transportation (vehicle emissions), natural sources (oceanic and volcanic activity), biological colonisation due to the production of sulphur by biological organisms (Saiz-Jimenez 1997; Warscheid and Braams 2000), and finally, the mortars and plasters used in construction are sometimes held responsible for gypsum formation (Rolland 1999; Kloppmann et al. 2011).

To study the degradations involving sulphur, for example, in the case of urban pollution, cycles of artificial ageing are commonly performed in the laboratory (Török et al. 2011). The work of Grossi et al. (2003) and Gomez-Heras et al. (2008) focused on visual effects such as chromatic changes, whereas other researchers have studied gypsum surface coatings in terms of the kinetics of sulphate deposition and adsorption and of gypsum formation (Ausset et al. 1996; Grossi and Murray 1999; Bai et al. 2006; Sanjurjo Sánchez et al. 2011). Laboratory tests consist of exposing stone samples continuously to realistic or non-realistic levels of gaseous $\mathrm{SO}_{2}$ in climatic chambers. Catalyst accelerators (particles, nitrogen oxides) are sometimes added to the mix (Haneef et al. 1993; Ausset et al. 1996). Only a few ageing protocols have involved gypsum solution (Pauly 1990; Prick 1996) and none has used solutions of sulphuric acid. Each time, the results led to the same conclusion; irrespective of the source of pollution, its concentration and the transmission protocol, gypsum is only ever found on the surface of the stone in a layer less than 2 mm thick.

This paper presents an original experimental campaign that includes artificial ageing to simulate in the laboratory the distribution of gypsum observed in samples subjected to spalling. The objective is to determine the most probable mechanism for the formation and penetration of gypsum in degraded stones, and to propose the consecutive sequences constituting the process of spalling, taking into account the source of the gypsum and its transport through the stone. 


\section{Experimental work}

Artificial ageing tests using partial imbibition / drying cycles at $20^{\circ} \mathrm{C}$ were performed on samples extracted from the Usseau quarry (Vienne, France), whose phisico-chemical properties are in the middle range of those of the tuffeau in Chambord. Samples were cylinders of $2.5 \mathrm{~cm}$ diameter and $3 \mathrm{~cm}$ length. This size makes it possible to optimize the time necessary for the drying stage, and this volume is sufficient to be representative of the material which is a fine-grained limestone (grain size does not exceed $0.2 \mathrm{~mm}$ ). Partial imbibition was obtained by capillary rise until half the height of the sample was reached. The capillary rise was obtained by placing the sample on a grid in contact with the solution such that only one face (i.e., the base of the cylinder) was in contact with the water, to simulate in situ imbibition due to water, the amplitude of which was of the order of $2 \mathrm{~cm}$ (Beck and Al-Mukhtar 2010). The imbibition was done parallel to the bedding plane to reproduce what actually happens when rainwater percolates through stone, typical of that used in a monument.

\subsection{First parameter: origin of gypsum}

To simulate different origins of gypsum, the chosen concentrations were high and non-realistic to accelerate the kinetics of the mechanisms involved. The chosen protocols aimed to reproduce three different forms of deposits, as described in the literature, either by wet or by dry process.

- Deposit of gypsum particles due to rainfall or runoff (wet deposit). The gypsum uptake consists of capillary rise by using a solution of water with gypsum in excess. The temperature of the solution was set at $40{ }^{\circ} \mathrm{C}$ to increase gypsum solubility (2.1 g/L). A temperature higher than this decreases the solubility (Charola et al. 2007). This saturated solution avoids any dissolution of gypsum during the cycles.

- Atmospheric pollution by acidic rain (wet deposit). The addition of sulphuric acid was provided by capillary rise by using a solution of $\mathrm{H}_{2} \mathrm{SO}_{4}$ at $\mathrm{pH}=2$. This value of $\mathrm{pH}$ is an optimal value below which the efficiency of the chemical reaction decreases, while the dissolution of calcite and gypsum formation is maximal (Charola et al. 2007).

- Atmospheric pollution by sulphur dioxide (dry deposit). $\mathrm{SO}_{2}$ injection was made by using dry gas in a vacuum-dried sample. The pore volume of the sample was saturated by gaseous SO2 before being submitted to the partial capillary rise of distilled water.

\subsection{Second parameter: pre-existing cracks in the stone}

To establish and understand the relationship between the occurrence of gypsum and pre-existing cracks, several cases were studied. Samples were prepared in three different ways to reproduce the three possible in situ situations, as shown in Figs. 2 and 3.

- Cracks parallel to the surface submitted to imbibition (1). Located at $1 \mathrm{~cm}$ depth, these cracks aimed to simulate the hypothesis of the existence of spalling-related cracks prior to the formation of gypsum, to verify whether such cracks could promote the observed distribution of gypsum.

- Cracks perpendicular to the surface submitted to imbibition (2). This case simulated some observed cracks, for example, on the corner of pilasters, which offer direct access for the transmission of pollutants.

- Undamaged specimen (3). This reference state was tested to study how gypsum propagates without any preexisting network of cracks.

Cracks were made by fracturing the samples (with chisel and hammer). To ensure the preferential direction of the crack, a notch $1 \mathrm{~mm}$ deep was made with a saw. The aim is to obtain a fresh fracture, and not a sawn surface. The two fragments were then reassembled and held together firmly and permanently with nylon wire. 


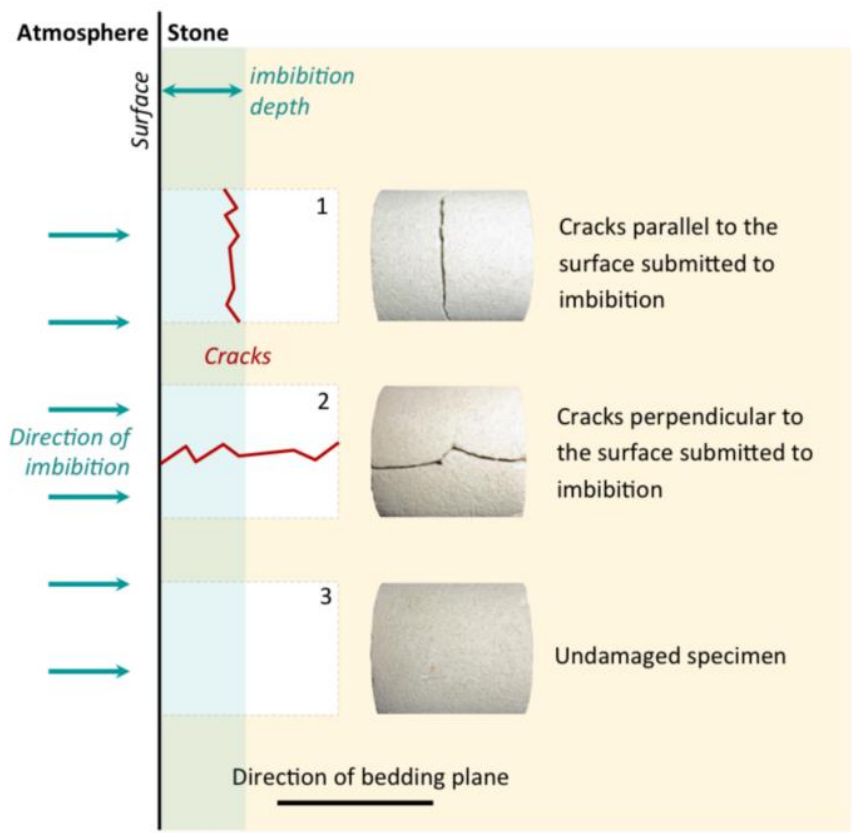

Figure 2. Schematic representations and photographs of the three types of initial sample cracking

\subsection{Third parameter: drying conditions}

Drying was performed in an oven at $40{ }^{\circ} \mathrm{C}$ to avoid any conversion of the gypsum $\left(\mathrm{CaSO}_{4} .2 \mathrm{H}_{2} \mathrm{O}\right)$ into bassanite $\left(\mathrm{CaSO}_{4} .1 / 2 \mathrm{H}_{2} \mathrm{O}\right)$, because higher temperatures progressively promote this conversion (Charola et al. 2007). The sample was considered dry when the weight was constant. Different conditions of sample insulation were tested to study its effect on the accumulation of gypsum near the surface submitted to imbibition. Insulation operated during drying only and it was removed during imbibition. The three tested conditions are summarised in Fig. 3.

- Without insulation (1). Evaporation can progress in all directions, as observed on corner stones or sculptures.

- Insulation covering all the faces but not the surface submitted to imbibition (2). These boundary conditions promote a unidirectional propagation of water movements to simulate the situation typical of stones in walls with drying towards the outdoor side.

- Insulation covering all the faces but not the surface opposed to imbibition (3). This variant of the second case aimed to reproduce a drying of the stone walls towards the indoor side. This situation is assumed possible because tuffeau is very permeable.

\subsection{Experimental protocol and measurement sequence}

Fig. 3 summarises the experimental plan and the range of variation of the different parameters studied. To assess the distribution of gypsum with depth, crystallographic and chemical analyses were performed at different steps in the artificial ageing.

- A set of samples was analysed at the end of the first imbibition. For this first analysis, the sample was not ovendried but frozen in liquid nitrogen and then lyophilised. The objective was to observe the gypsum distribution just after the first sulphur-related uptake and before any drying occurs.

- Another set of samples was analysed just at the end of cycle one with drying included, to determine the effect of drying in comparison with the first set. 
- A third set of samples was analysed after 10 cycles of sulphur-related uptake to study the accumulation of gypsum.

- $\quad$ Finally, a set of samples was analysed after being submitted to the first sulphur-related uptake and then nine cycles of imbibition/drying using distilled water exclusively, to study the "tide" effect due to successive drawdown.

Once the four different protocols had been applied, cylindrical samples were split according to a longitudinal plane passing through the diameter and then powder samples were collected at various depths.

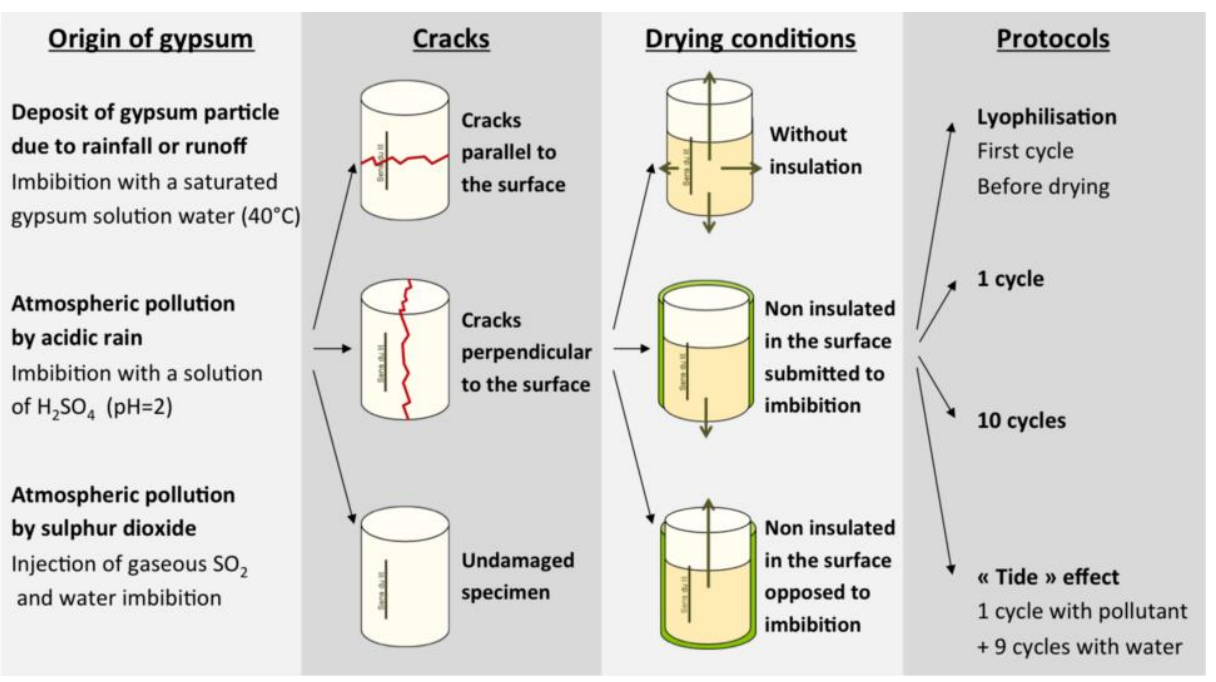

Figure 3. Summary of the experimental plan

X-ray diffraction (XRD) was used to characterise the different crystalline phases and more specifically, to detect the presence of gypsum. The measurement was performed from a $2 \theta$ angle of $4^{\circ}$ up to $60^{\circ}$ with a step time of $0.025^{\circ}$ every 6 seconds. Diffractograms were obtained with the Ka ray of Copper $\left(\lambda_{c u}=1.5406 \AA\right)$. Qualitative XRD analyses were complemented by ion chromatography to quantify the sulphate concentration. For this objective, samples were prepared according to the Normal, 1983. This standard states that samples must be ground and then solubilised in deionised water with a concentration of $1 \mathrm{~g}$ of sample for $100 \mathrm{~mL}$ of water and then shaken for 72 hours. After filtration of the resulting solution in a $45-\mu \mathrm{m}$ membrane, the cations $\left(\mathrm{Na}^{+}, \mathrm{Ca}^{2+}, \mathrm{Mg}^{2+}, \mathrm{K}^{+}\right)$and anions $\left(\mathrm{Cl}^{-}, \mathrm{SO}_{4}{ }^{2-}\right.$ and $\left.\mathrm{NO}_{3}{ }^{-}\right)$were quantified.

\section{Results}

\subsection{Gypsum detection}

All samples analysed by XRD showed the usual minerals that can be observed in tuffeau (calcite, quartz, opal-CT and glauconite). For all protocols of sulphur-related uptake, the presence of gypsum was always observed, as shown in Fig. 4. The X-ray diffractograms highlight that the sulphur was found only in the form of gypsum, because neither bassanite nor anhydrite were observed. Hence, all the sulphates quantified by ion chromatography were attributed to gypsum. To simplify the display of the results, only the XRD quantification of gypsum is presented. 


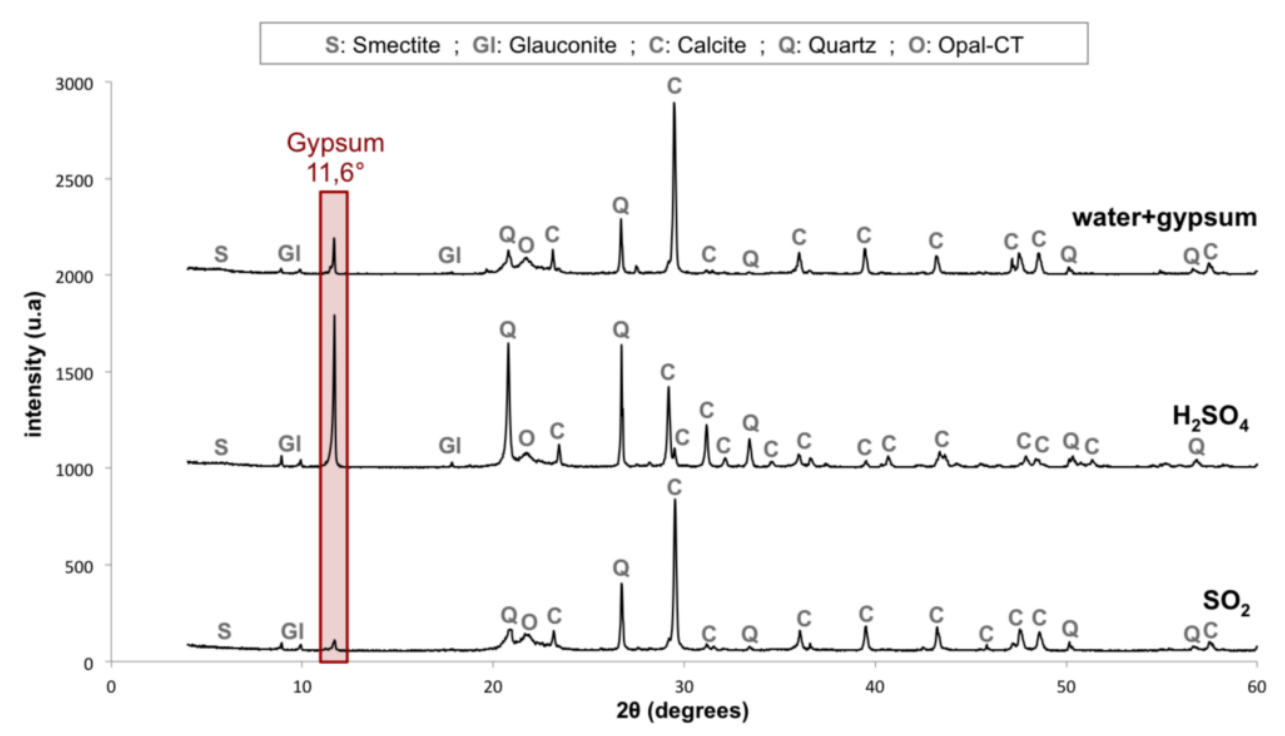

Figure 4. X-ray diffractogram on powder for the three types of sulphur-related uptake

\subsection{Effect of gypsum solution}

Table 1 presents the results of the ion chromatography analysis made on samples subjected to the partial imbibition $(1.5 \mathrm{~cm})$ of the saturated gypsum solution. In this first protocol of sulphur-related uptake, the accumulation of gypsum was found almost exclusively on the surface. After 10 cycles involving gypsum solution, the concentrations reached $4 \%$ by weight at the surface and less than $0.5 \%$ in the core.

\begin{tabular}{|c|c|c|c|c|}
\hline & \multicolumn{4}{|c|}{ Gypsum concentration by weight } \\
\hline & surface & 1 -cm depth & 2-cm depth & 3 -cm depth \\
\hline Lyophilisation & $0.5 \%$ & $<0.1 \%$ & $<0.1 \%$ & $<0.1 \%$ \\
\hline 1 cycle & $0.5 \%$ & $<0.1 \%$ & $<0.1 \%$ & $<0.1 \%$ \\
\hline $\mathbf{1 0}$ cycles & $\mathbf{3 . 9 \%}$ & $\mathbf{0 . 1} \%$ & $\mathbf{0 . 2} \%$ & $\mathbf{0 . 5 \%}$ \\
\hline Tidal effect & $0.3 \%$ & $<0.1 \%$ & $<0.1 \%$ & $<0.1 \%$ \\
\hline
\end{tabular}

Table 1. Gypsum concentration (by weight) in samples not insulated, initially undamaged and subjected to the protocol involving saturated gypsum solution.

Samples that were lyophilised just after the first partial imbibition and samples that were subjected to the partial imbibition and subsequent drying showed the same concentrations; around $0.5 \%$ by weight on the surface and less than $0.1 \%$ in the core. Analysis on lyophilised samples proved that even without drying (causing liquid water transport to the evaporating surface), gypsum is always located on the imbibition surface. Moreover, promoting tidal phenomena did not change the gypsum distribution because the concentrations were still the same after adding nine cycles of imbibition / drying of distilled water.

Hence, samples subjected to 1 cycle of gypsum solution (lyophilised after imbibition; cycle 1; cycle $1+$ tidal effect) and samples subjected to 10 cycles presented the same shape of distribution with a higher content for 10 cycles. This accumulation is the consequence of the increased uptake in gypsum solution. In the literature, artificial ageing tests using saturated gypsum solution applied on tuffeau proposed the same conclusion; the surface concentration (less than $1 \mathrm{~mm}$ depth) increases with the cycles but no gypsum can be observed in the core, even after more than 100 cycles (Pauly 1990; Prick 1996).

Concerning the other studied parameters, illustrated on figure 5, no significant change was observed because of the different types of drying conditions or initial cracking. In all cases, the amounts of gypsum were very similar to those 
presented in Table 1. For this ageing involving saturated gypsum solution, the drying conditions and initial cracking did not affect the resulting distribution of the gypsum.

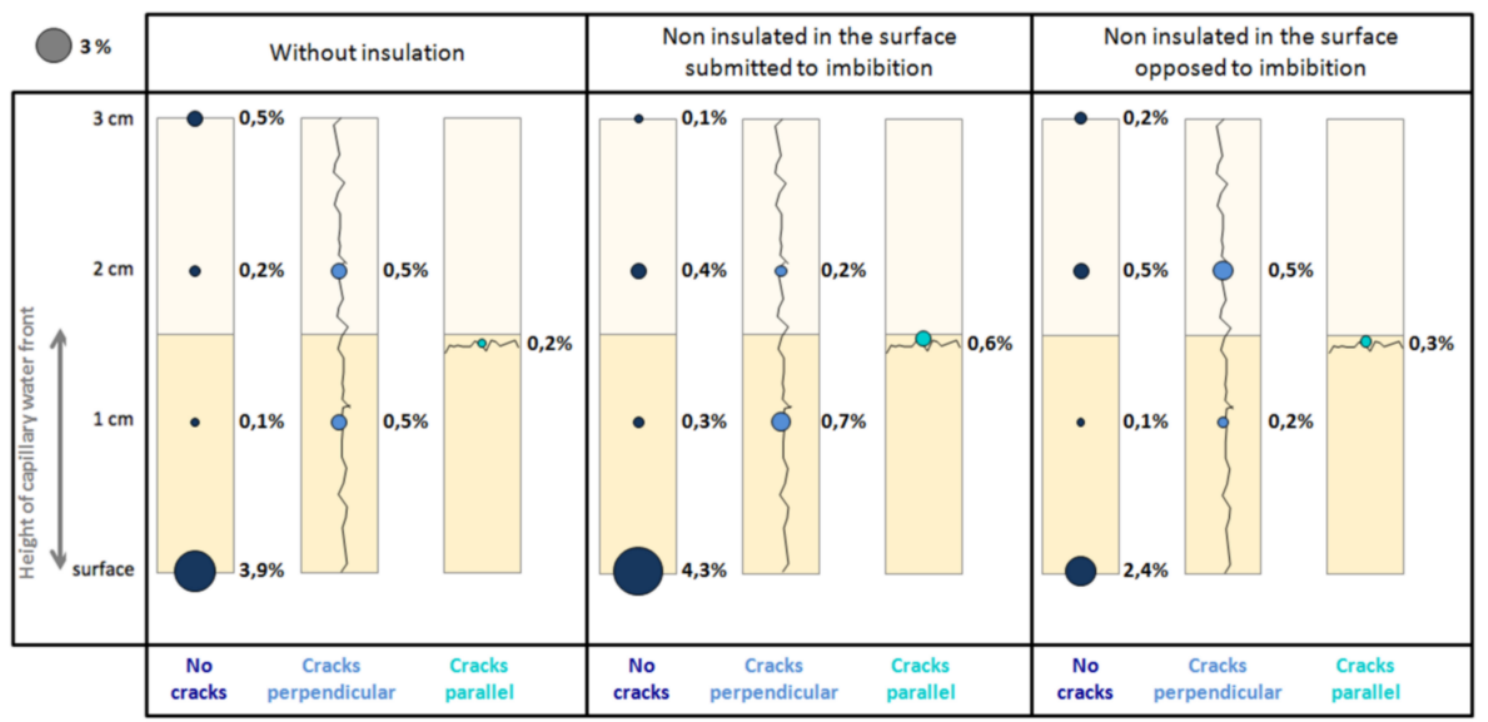

Figure 5. Schematic representation of the gypsum concentration (by weight) in samples subjected to the 10 cycles protocol involving saturated gypsum solution: influence of insulation and cracks

\subsection{Effect of $\mathrm{H}_{2} \mathrm{SO}_{4}$ solution}

Table 2 presents the results of ion chromatography analysis made on samples subjected to the partial imbibition $(1.5 \mathrm{~cm})$ of $\mathrm{H}_{2} \mathrm{SO}_{4}$ solution at $\mathrm{pH}=2$. The overall aspect of the gypsum distribution corresponds to the ageing involving saturated gypsum solution, i.e., the gypsum was observed only at the surface subjected to imbibition. However, the concentration was much higher in the case of the $\mathrm{H}_{2} \mathrm{SO}_{4}$ solution.

\begin{tabular}{|c|c|c|c|c|}
\hline & \multicolumn{4}{|c|}{ Gypsum concentration by weight } \\
\hline & surface & 1-cm depth & 2-cm depth & 3-cm depth \\
\hline Lyophilisation & $19.6 \%$ & $0.4 \%$ & $<0.1 \%$ & $0.1 \%$ \\
\hline 1 cycle & $21.3 \%$ & $0.5 \%$ & $0.1 \%$ & $0.2 \%$ \\
\hline $\mathbf{1 0}$ cycles & $\mathbf{2 5 . 4} \%$ & $\mathbf{1 . 1} \%$ & $\mathbf{0 . 4} \%$ & $\mathbf{1 . 2} \%$ \\
\hline Tidal effect & $18.8 \%$ & $0.3 \%$ & $<0.1 \%$ & $0.1 \%$ \\
\hline
\end{tabular}

Table 2. Gypsum concentration (by weight) in samples not insulated, initially undamaged and subjected to the protocol involving $\mathrm{H}_{2} \mathrm{SO}_{4}$ solution.

With regard to the lyophilised sample, the sample submitted to 1 cycle and the sample submitted to one cycle plus the tidal effect, the conclusions are similar to the case of saturated gypsum solution. Hence, we can conclude that gypsum formed during imbibition and that it was not moved during the drying or any further imbibition.

For samples subjected to 10 cycles of partial imbibition of $\mathrm{H}_{2} \mathrm{SO}_{4}$ solution and drying, the gypsum concentration reached $25 \%$ at the surface but only $1 \%$ in the core. The action of $\mathrm{H}_{2} \mathrm{SO}_{4}$ resulted in the creation of a highly gypseous crust at the surface with little effect at depth. The very high concentration observed just after the first cycle (around $20 \%)$ suggests that most of the gypsum formed during the first cycle. Because the calcite located at the surface had reacted completely with the sulphates, only a very limited amount of gypsum was formed during further cycles. 
This phenomenon of a gypseous crust is well known in the literature. For example, it occurs when samples are exposed to gaseous $\mathrm{SO}_{2}$ under wet conditions, resulting in the generation of $\mathrm{H}_{2} \mathrm{SO}_{4}$ solution at the surface of the tested stone (Ausset et al. 1996; Bai et al. 2006). As already stated in the introduction, literature tests confirm that irrespective of the duration of the exposure procedure or the number of cycles, gypsum accumulation is only found at the surface under ageing involving $\mathrm{H}_{2} \mathrm{SO}_{4}$ solution.

Figure 6 illustrates the other case of insulation and cracking. In the case of samples whose initial cracking was perpendicular to the surface, subjected to imbibition, the gypsum accumulation was very high on the rims of the crack (around 22\%), which was similar to the concentration at the surface. This direction of cracking promoted rising damp through the crack, resulting in exposure of the rims of the crack to the $\mathrm{H}_{2} \mathrm{SO}_{4}$ solution almost as quickly as that for the surface subjected to imbibition.

In contrast, the cracking parallel to the surface did not promote any accumulation of gypsum in the crack and the gypsum concentration was equal to that of the case of the initially undamaged samples (around 1\%). Similarly, sample insulation during drying did not change the gypsum distribution because the resulting concentrations were found to be similar to those of the non-insulated samples.

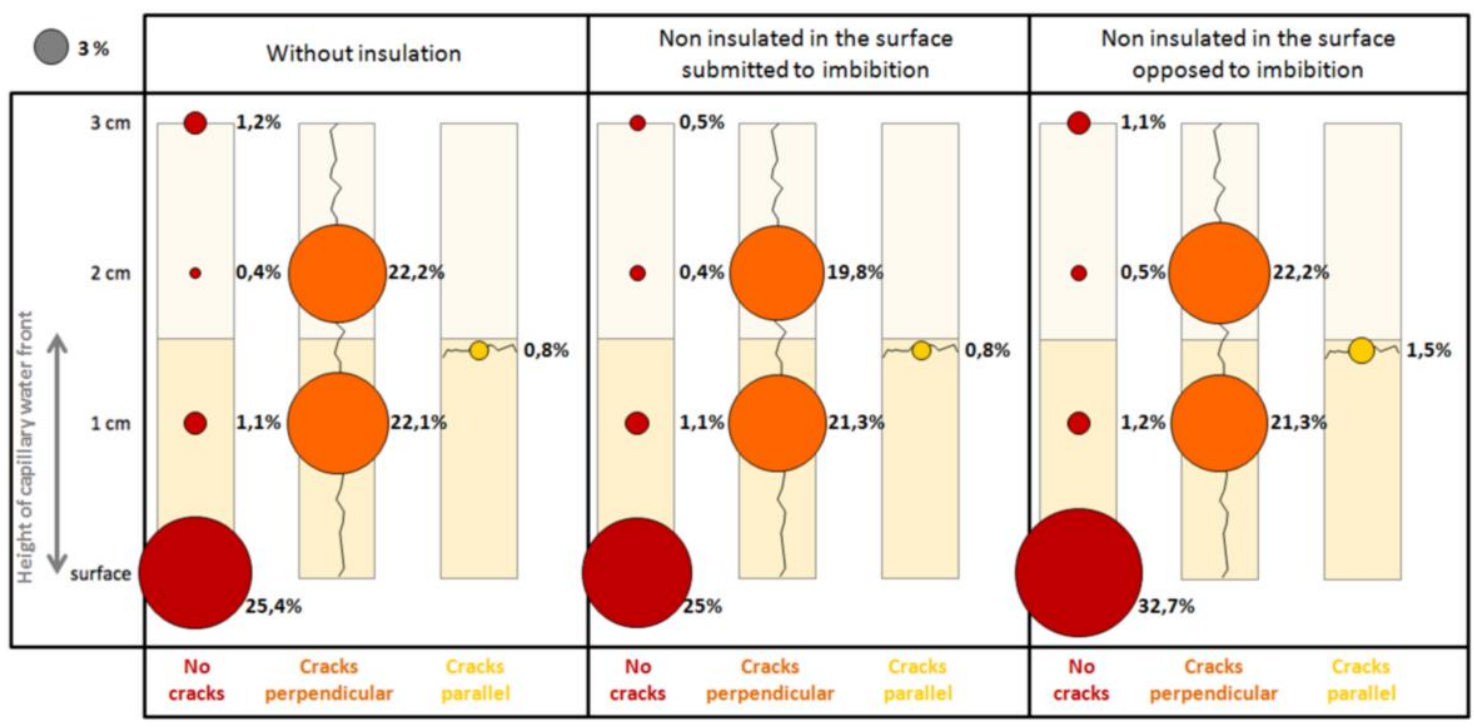

Figure 6. Schematic representation of the gypsum concentration (by weight) in samples subjected to the 10 cycles protocol involving $\mathrm{H}_{2} \mathrm{SO}_{4}$ solution: influence of insulation and cracks

\subsection{Effect of gaseous $\mathrm{SO}_{2}$}

Table 3 presents the results of the ion chromatography analysis made on samples subjected to the injection of gaseous $\mathrm{SO}_{2}$ under dry conditions, followed by partial imbibition $(1.5 \mathrm{~cm})$ of distilled water and then drying. Once again, the lyophilised samples, the samples submitted to one cycle and the samples submitted to tidal effects showed the same distribution of gypsum. Samples subjected to 10 cycles presented a similar overall trend but with much higher concentrations. 


\begin{tabular}{|c|c|c|c|c|}
\hline & \multicolumn{4}{|c|}{ Gypsum concentration by weight } \\
\hline & surface & 1 -cm depth & 2-cm depth & 3-cm depth \\
\hline Lyophilisation & $0.1 \%$ & $0.6 \%$ & $0.9 \%$ & $0.5 \%$ \\
\hline 1 cycle & $0.2 \%$ & $0.8 \%$ & $1 \%$ & $0.5 \%$ \\
\hline 10 cycles & $\mathbf{2 . 8} \%$ & $\mathbf{4} \%$ & $\mathbf{1 2 . 7} \%$ & $\mathbf{4 . 1} \%$ \\
\hline Tidal effect & $0.2 \%$ & $0.5 \%$ & $1 \%$ & $0.4 \%$ \\
\hline
\end{tabular}

Table 3. Gypsum concentration (by weight) in samples not insulated, initially undamaged and subjected to the protocol involving injection of gaseous $\mathrm{SO}_{2}$.

However, the distribution resulting from the injection of $\mathrm{SO}_{2}$ was very different from that resulting from gypsum solution or $\mathrm{H}_{2} \mathrm{SO}_{4}$ solution. The surface concentration, although significant (about 3\%), was much lower compared with the core concentration (between $4 \%$ and $12 \%$ ). It is interesting to emphasise that the concentration is highest in the zone corresponding to the limit of capillary water movements, at around $2 \mathrm{~cm}$ depth. The water supply by capillarity is stopped when the imbibition front reached $1.5 \mathrm{~cm}$ depth, and then it continues to migrate until reaching $2 \mathrm{~cm}$ depth. In addition, a significant concentration of gypsum (almost 4\%) was found on the face opposite to imbibition. This latter finding demonstrates that even if the capillary front has not reached a zone, the smallest pores of this zone can contain sufficient liquid water due to vapour movement and then condensation, to allow gypsum formation with previously adsorbed $\mathrm{SO}_{2}$.

Figure 7 shows that the conditions of insulation during drying did not have any effect on the concentration of gypsum measured in the core, whereas surface concentrations did seem to be affected. In the case of non-insulated samples, gypsum concentrations were quite similar whether they were measured on the surface submitted to imbibition or on the opposite surface. Conversely, insulated samples always showed higher gypsum concentrations on the surface not affected directly by drying. Concerning the importance or not of the pre-existing cracks, in the characterization of in situ samples on the castle of Chambord, it was shown that the gypsum content was higher in the crack (Janvier-Badosa et al. 2013b). Questions arising from this are: what took place first, gypsum formation or cracking? Does the presence of a crack cause the preferential accumulation of gypsum in this place? According to our tests, it would seem not.

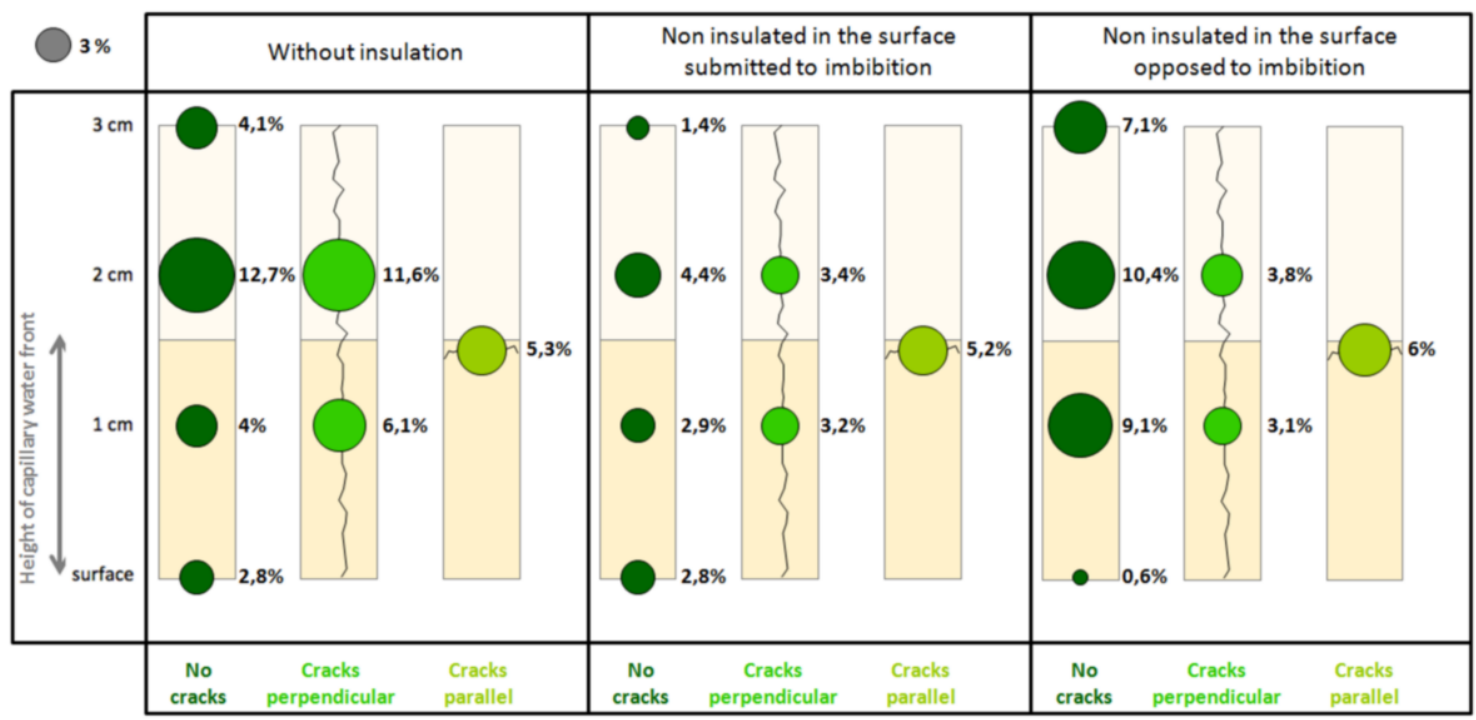

Figure 7. Schematic representation of the gypsum concentration (by weight) in samples subjected to the 10 cycles protocol involving injection of gaseous $\mathrm{SO}_{2}$ : influence of insulation and cracks 


\section{Discussion}

\subsection{Comparison between in situ actual ageing and laboratory artificial ageing}

For both protocols involving wet deposit (i.e., saturated gypsum and $\mathrm{H}_{2} \mathrm{SO}_{4}$ solution), the maximum gypsum accumulation was found at the surface submitted to imbibition; a dramatic decrease in concentration was observed in the core. The only exception to this was limited to those samples exposed to $\mathrm{H}_{2} \mathrm{SO}_{4}$ with an initial cracking perpendicular to the surface, submitted to the imbibition. In this particular situation, the crack allowed direct access for rising damp of $\mathrm{H}_{2} \mathrm{SO}_{4}$ solution, resulting in gypsum formation on the rims of the crack, as if it were a surface of imbibition. For the protocol involving dry deposit (injection of gaseous $\mathrm{SO}_{2}$ ), the opposite was observed; the highest concentration was measured in the core zone, corresponding to the limit of capillary water movements and only a small amount of gypsum accumulation was observed at the surface.

Stones subjected to spalling at the Castle of Chambord that were cored and analysed, showed very little concentration of gypsum at the surface and then increasing concentrations with depth, until the crack was reached where the concentration was found to be maximal. Then, the concentration decreased progressively (Fig. 8) (JanvierBadosa et al. 2013b). By comparison with other in situ observations, the crack appeared located at the limit of capillary water movement (Beck and Al-Mukhtar 2010). This gypsum distribution corresponds to the one obtained by the protocol of dry deposit involving the injection of gaseous $\mathrm{SO}_{2}$ and then partial imbibition of water, as presented in Table 3.
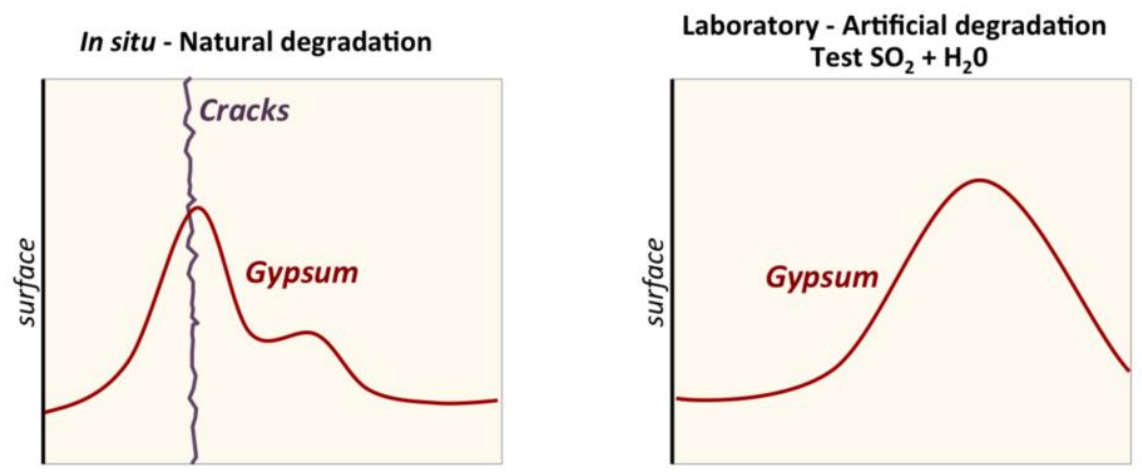

Figure 8. Schematic representation of the gypsum distribution observed in in situ cored samples subjected to spalling and samples submitted to dry deposit of gaseous $\mathrm{SO}_{2}$ in laboratory

\subsection{Hypothesis concerning origin of gypsum}

The systematic presence of gypsum in stones of the Castle of Chambord that have been subjected to spalling raises the question about the source of gypsum. From the environmental point of view, natural sources (oceanic and volcanic activity) can be neglected because the Castle of Chambord is geographically distant from any such sources. Moreover, the production of sulphur by biological organisms (Saiz-Jimenez 1997; Warscheid and Braams 2000) is considered an irrelevant hypothesis because high quantities of gypsum have been observed in walls with no biological colonisation. Furthermore, no mortars and plaster joints used in construction have been observed in the outer walls of the Castle of Chambord and the analysis of mortars of the masonry joints have shown no gypsum content in their compositions (Janvier-Badosa 2012). However, even if the level of sulphur content found in today's atmosphere is insufficient to explain the observed gypsum content in the stone, past pollution can often be implicated in the degradation of built cultural heritage (Brimblecombe and Grossi 2009). Pyrite, which is a sulphur-containing mineral and present locally in tuffeau (Pauly 1990; Verges-Belmin et al. 2001), is not considered a sufficient source of sulphur to explain the systematic formation of gypsum.

In the stone of the Castle of Chambord, the influence of air pollution concerning Blois cannot be neglected as Chambord is located close to Blois (about $15 \mathrm{Km}$ ). Measurements at the Castle of Blois reach more than $20 \%$ by weight 
(Janvier-Badosa, 2012) and in Chambord stones the sulphate content is about 1.5\% (Janvier-Badosa et al. 2013b). The measured $\mathrm{SO}_{2}$ levels nowadays are constant from one year to another, and less than $1 \mu \mathrm{g} / \mathrm{m} 3$. The latest measurements carried out in 2007 indicated that gypsum contents in the atmosphere are negligible. In addition, statistical analyses of the distribution of spalling on the facades of the castle as a function of the date of construction and restoration were performed. This study shows that no stone restored from the early twentieth century exhibits spalling (Janvier-Badosa et al., 2014). In addition, samples taken from healthy stones also restored from the early twentieth century show no presence of gypsum in depth. This suggests that a source of gypsum existed in the past, prior to 1900. Finally, samples were taken on the castle of Chambord sculptures that were removed in 1884 (Desbois, 1894). The sculptures were kept inside the castle from that date on (thus protected from pollution). These samples show the presence of gypsum in flaking at the surface of the stone, with concentrations of about $5 \%$.

All the results and data collected during studies on Chambord castle point to the hypothesis of past air pollution as the origin of gypsum in the stone of the castle. It would be possible to identify the exact provenance of gypsum by analysing the sulphur isotope, as described in the work by Vallet et al. 2006 and Kloppmann et al. 2011.

\subsection{Proposal of a mechanism of gypsum formation}

As the last artificial ageing protocol relative to injection of gaseous $\mathrm{SO}_{2}$ at dry state seems the most probable source of sulphates to simulate the in situ observations of stone subjected to spalling, a mechanism of gypsum formation based on this protocol is proposed (Fig. 9). This mechanism builds on literature data (Charola et al. 2007) and on conclusions from observations of artificially aged samples and samples of in situ weathered stones.

A three-step process is proposed to explain the formation of gypsum:

1) Gaseous $\mathrm{SO}_{2}$ from air pollution enters the stone's porous network in a dry state by diffusion.

2) During a wetting event, imbibition progresses into the stone and the previously absorbed $\mathrm{SO}_{2}$ is pushed to greater depth until the imbibition stops.

3) During this period of low kinetics of water movement, the $\mathrm{SO}_{2}$ has sufficient time to dissolve into the water front, form $\mathrm{H}_{2} \mathrm{SO}_{4}$ and then precipitate directly into gypsum following dissolution of the calcite.

Thus, the resulting gypsum distribution is located preferentially at the limit of capillary water movement, which is typically at about $2 \mathrm{~cm}$ depth in the case of outdoor walls built using tuffeau. With the drying conditions used for testing, since gypsum has a low solubility and low mobility (Hammecker 1995), gypsum remains where it crystallized. It moves very little during the movement of water caused by drying, unlike other soluble salts, such as $\mathrm{NaCl}_{\text {or }} \mathrm{Na}_{2} \mathrm{SO}_{4}$ which can cause efflorescences (Hammecker 1995, Van et al. 2007).

Artificial ageing tests showed that even if the capillary imbibition is stopped when liquid water reaches $1.5 \mathrm{~cm}$ depth, the capillary water front still progresses until $3 \mathrm{~cm}$ depth and gypsum can be found up to a depth of $3 \mathrm{~cm}$ where no capillary water due to capillary rise is available. Similar observations were obtained from the analysis of samples cored in the castle; they contain significant although low concentrations of gypsum beyond the imbibition limit (JanvierBadosa et al. 2013b). This means that capillary condensation associated with vapour transfer through the porous network of the stone can provide sufficient liquid water to allow gypsum formation. 

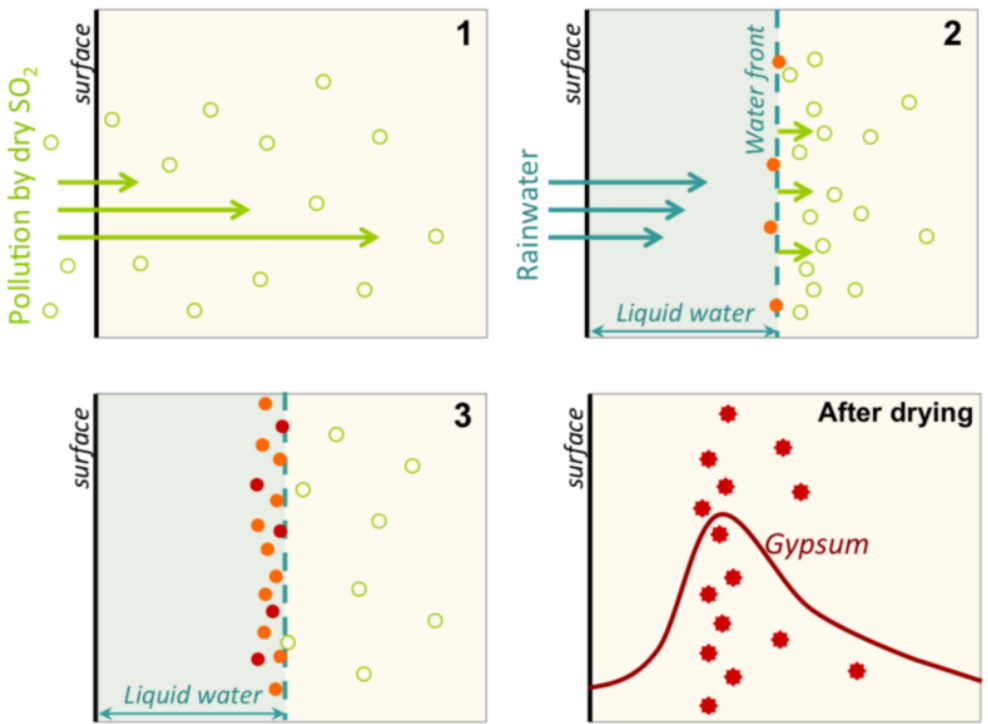

Figure 9. Description of a mechanism that explains how gypsum forms by taking into account sulphur uptake by gaseous $\mathrm{SO}_{2}$ in a dry state

\subsection{Proposal of a mechanism of spalling development}

Based on the proposed mechanism of gypsum formation, a mechanism for the development of spalling is proposed, in the case of fine and very porous calcareous stones such as tuffeau. Fig. 10 presents a chronology of spalling development and specifies the different steps identified in the process from healthy stone until the plaque finally drops.

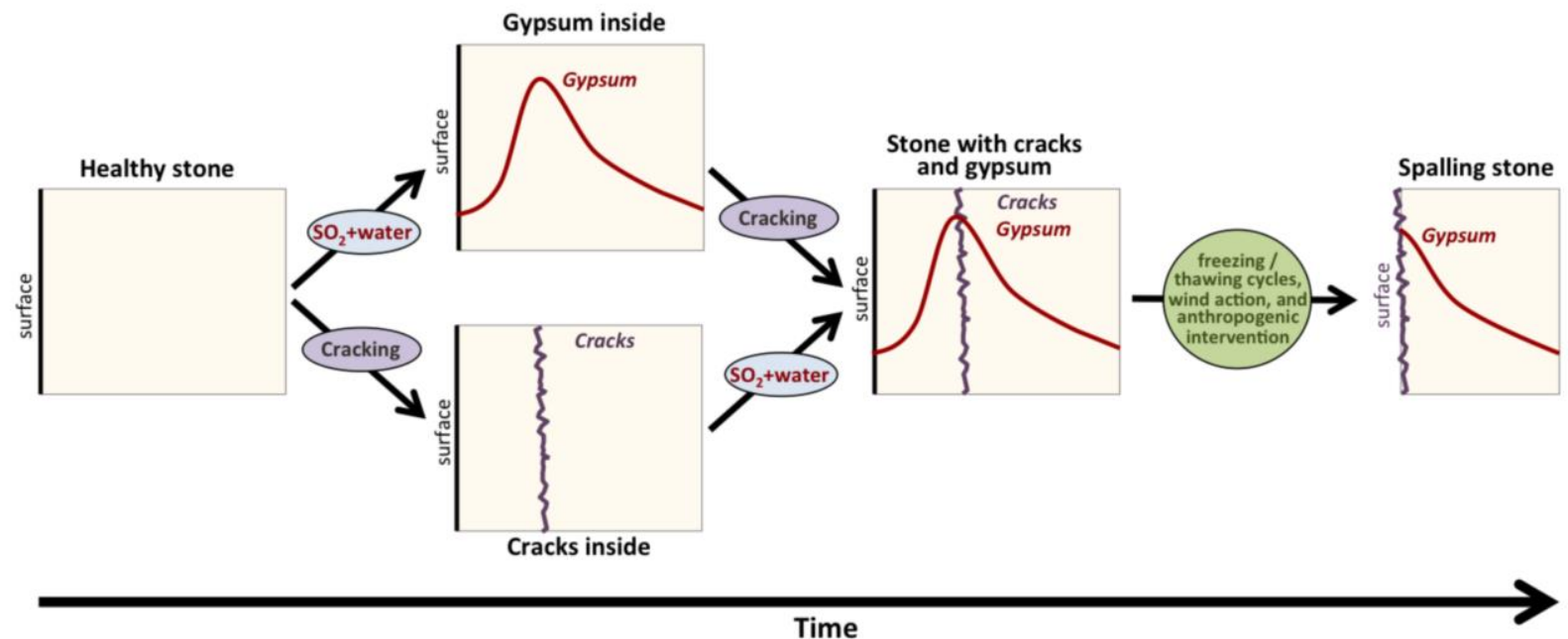

Figure 10. Description of a mechanism that explains how plaque develops in tuffeau subjected to spalling

When a stone is subjected to spalling, two different phenomena are observed: a crack is found at $1 \mathrm{~cm}$ depth and gypsum accumulates in this crack. Taken separately, the gypsum accumulation is likely the result of gaseous $\mathrm{SO}_{2}$ uptake in a dry stone followed by water imbibition due to a rain event. Crack initiation could be caused by mechanical fatigue stress due to thermal-hydraulic differential dilation between the surface and the core which can be amplified by the presence of significant amounts of clayey minerals in tuffeau. These two phenomena are related to the depth of penetration of rain water: gypsum accumulates on the capillary water front, and the crack is also formed at the capillary water front. It is possible that these two phenomena are independent, and that they occur at the same time without any temporal or cause and effect relationship. However, the question of the relative chronology and of the cause and effect relationship between the two phenomena remains: did the gypsum accumulate before the crack appeared, or 
did it form afterwards? In the case of plaques sampled from the Castle of Chambord, gypsum was found systematically in the cracks (Janvier-Badosa et al. 2013b). In some apparently healthy stones located near damaged ones, gypsum was found at $1 \mathrm{~cm}$ depth, despite there being no visible crack. Moreover, artificial ageing tests showed that initial cracking did not promote gypsum accumulation in the crack. These findings are in accordance with the conclusion that the accumulation of gypsum is more probably prior to cracking. With regard to the cause and effect relationship, there is no real evidence yet. However, two hypotheses can be put forward: (1) gypsum accumulation can contribute to generating heterogeneities in the local material' properties, increasing the stress induced by differential thermal-hydraulic dilation between the surface and the core and (2) subsequent and numerous cycles of imbibition / drying can promote gypsum localisation in the crack by Ostwald ripening, preventing the crack from closing during the cycles and promoting its extension due to local concentration of stress at the crack tip.

The ultimate fall of the plaque could be caused by several external factors, such as freezing / thawing cycles, wind action and any human intervention on the wall, such as the creation of openings or even vandalism.

\section{Conclusion and perspectives}

This study focused on providing some new data to improve our knowledge of spalling development and gypsum formation in fine and very porous limestone by performing an original experimental campaign of artificial ageing.

The protocols of artificial ageing based on partial imbibition followed by drying involved several parameters: initial cracking (parallel to the imbibed surface; perpendicular; no cracking), drying conditions (insulated but imbibed surface, insulated but opposite surface, no insulation) and type of pollution (saturated gypsum solution; $\mathrm{H}_{2} \mathrm{SO}_{4}$ solution at $\mathrm{pH}=$ 2 ; injection of gaseous $\mathrm{SO}_{2}$ at dry state). Some samples were analysed prior to the first drying thanks to lyophilisation, some others were analysed after the first cycle with drying included, others were submitted to 10 cycles and a final set was submitted to 1 cycle followed by 9 cycles of partial imbibition of distilled water and drying (tidal test).

No significant differences were observed between the samples of lyophilisation, one cycle and one cycle followed by the tidal test. Moreover, there was no effect observed attributable to drying conditions. Finally, applying 10 cycles resulted in an increase of the concentrations of gypsum without changing the overall trend of the distribution. All these first observations prove that gypsum, in this condition of imbibition and drying, precipitates quickly and that the gypsum cannot be dissolved easily for any subsequent crystallisation and redistribution.

The two protocols involving a wet deposit (i.e., saturated gypsum solution and $\mathrm{H}_{2} \mathrm{SO}_{4}$ solution) resulted in the accumulation of gypsum at the surface submitted to imbibition with no significant precipitation deeper in the stone. The protocol of ageing involving $\mathrm{H}_{2} \mathrm{SO}_{4}$ led to the highest concentration of gypsum, up to $25.4 \%$ by weight at the surface after 10 cycles; the protocol involving saturated gypsum solution only reached $4 \%$ under the same conditions.

The only protocol that allowed the gypsum to precipitate significantly deep into the stone was the dry deposit of gaseous $\mathrm{SO}_{2}$, followed by partial imbibition of distilled water. Following this protocol, up to $12.7 \%$ of gypsum was observed at $2 \mathrm{~cm}$ depth after 10 cycles with much lower concentrations at the imbibed surface (2.8\%). This latter distribution corresponds to the distribution of gypsum observed in samples cored in the Castle of Chambord that have been subjected to spalling.

The tests showed that the crack did not play any role in the preferential localization of gypsum. The only counterexample was in the case of initial cracking perpendicular to the imbibed surface with the protocol of $\mathrm{H}_{2} \mathrm{SO} 4$ solution. In this particular situation, the sulphuric acid solution entered directly into the crack by capillary rise, resulting in a massive precipitation of gypsum on the rims of the crack (as if they were the imbibed surface) with no significant precipitation of gypsum in the rest of the stone.

One of the main aims of this study was to prove that it is possible to precipitate a significant amount of gypsum in the core of the stone and thus, simulate the distribution of gypsum observed on in situ samples subjected to spalling, by using a dry deposit of $\mathrm{SO}_{2}$ followed by partial imbibition of water. Hence, atmospheric pollution is likely to be the source of the sulphur that leads to the presence of gypsum in the core of the stone at the Castle of Chambord. In fact, various observations, collected data and experimental results presented in this study converge toward the hypothesis of atmospheric pollution as the origin of gypsum in the stone of the castle. However, while the source of this pollution is difficult to determine, the date seems ancient, maybe before 1900. 
Based on this hypothesis of a gaseous pollution by $\mathrm{SO}_{2}$, a mechanism that explains how gypsum forms, by considering sulphur uptake by gaseous $\mathrm{SO}_{2}$ in a dry state, is proposed. When imbibition progresses into the stone, the previously absorbed $\mathrm{SO}_{2}$ is pushed to a greater depth until the imbibition stops. During this period of low kinetics of water movement, the $\mathrm{SO}_{2}$ has sufficient time to dissolve into the water front, form $\mathrm{H}_{2} \mathrm{SO}_{4}$ and precipitate directly into gypsum after dissolution of the calcite. Thus, the resulting distribution of gypsum is located preferentially at the limit of capillary water movement, which is typically at about $2 \mathrm{~cm}$ depth in the case of outdoor walls built using tuffeau.

Finally, based on this mechanism of gypsum formation, a mechanism that explains how plaque develops in tuffeau subjected to spalling is proposed. Firstly, two phenomena occur: cracking at about $2 \mathrm{~cm}$ depth and gypsum formation in the same area. The gypsum formation is likely to be caused by the dry deposit of $\mathrm{SO}_{2}$, whereas the cracking could be due to mechanical fatigue resulting from differential dilatation between the surface and the core of the stone. The interactions between the two phenomena are not clearly demonstrated by this study. As a perspective of this work, it would be interesting to carry out a large number of imbibition/drying cycles to highlight the mechanical fatigue stress of materials, with expansion gauges. These tests could be coupled or not with gypsum pollution (gaseous $\mathrm{SO}_{2}$ ) to establish the relationship between the two phenomena, and evaluate whether the gypsum could cause or accelerate cracking.

\section{References}

Ausset P, Crovisier JL, Del Monte M, Furlan V, Girardet F, Hammecker C, Jeannette D, Lefevre RA (1996) Experimental study of limestone and sandstone sulphation in polluted realistic conditions: The Lausanne Atmospheric Simulation Chamber (LASC). Atmospheric Environment 30(18):3197-3207

Bai Y, Thompson GE, Martinez-Ramirez S (2006) Effects of $\mathrm{NO}_{2}$ on oxidation mechanisms of atmospheric pollutant $\mathrm{SO}_{2}$ over Baumberger Sandstone. Building and Environment 41(4):486-491

Beck K, Al-Mukhtar M, Rozenbaum O, Rautureau M (2003) Characterisation, water transfer properties and deterioration in tuffeau: building material in the Loire valley-France. International Journal of Building and Environment 38(9):1151-1162

Beck K, Al-Mukhtar M (2005) Multi-scale characterisation of two French limestones used in historic constructions. Int J of Restoration 11(4):219-226

Beck K, Al-Mukhtar M (2010) Weathering effects in an urban environment: a case study of a French porous limestone. Geological Society, London, SP 2010 (doi 10.1144/SP331.8) 331:103-111

Benavente D, Cultrone G, Gomez-Heras M (2008) The combined influence of mineralogical, hygric and thermal properties on the durability of porous building stones. European Journal of Mineralogy. 20:673-685

Berthonneau J, Grauby O, Bromblet P, Vallet JM, Dessandier D, Baronnet A (2012) Role of swelling clay minerals in the spalling decay mechanism of the "pierre du midi" limestone (South-East of France). $12^{\text {th }}$ International Congress on the Deterioration and Conservation of Stone, 22-26 October 2012, New York, USA

Brimblecombe P, Grossi CM (2009) Millennium-long damage to building materials in London. Science of the Total Environment, 407(4):1354-1361

Brunet-Imbault B (1999) Etude des patines de pierres calcaires mises en œuvre en région Centre, French Ph-D thesis, University of Orléans

Cautru JP (1976) Le Tuffeau de Touraine - Étude de son altération, French report, BRGM Orléans - 76 SGN 012 MTX

Charola AE, Puhringer J, Steiger M (2007) Gypsum: a review of its role in the deterioration of building materials. Environ.Geol. 53:339-352

Colas E, Mertz JD, Thomachot-Schneider C, Barbin V, Rassineux F (2011) Influence of the Clay Coating Properties on the Dilation Behavior of Sandstones. Applied Clay Science 52(3):245-252

Desbois, Father and Son (1894) Notice des travaux de restauration exécutés au château de 1882 à 1894. Paris 
Gomez-Heras M, Smith BJ, Viles HA (2008) Laboratory modelling of gypsum crust growth on limestone related to soot pollution and gaseous sulphur: Implications of 'cleaner' environments for stone decay. 11th International Congress on Deterioration and Conservation of stone, Torun, Pologne

Grossi CM, Murray M (1999) Characteristics of carbonate building stones that influence the dry deposition of acidic gases. Construction and Building Materials 13(3):101-108

Grossi CM, Esbert RM, Díaz-Pache F, Alonso FJ (2003) Soiling of building stones in urban environments. Building and Environment 38(1):147-159

Gutiérrez J, Mas A, Gil E, Galvañ V (2012) Clay-related damage in rainscreen walls built with natural stone coverings. Construction and Building Materials 29:357-367

Hammecker C (1995) The importance of the petrophysical properties and external factors in the stone decay on monuments. Pure and Applied Geophysics PAGEOPH 145(2):337-361

Haneef SJ, Johnson JB, Jones M, Thompson GE, Wood GC, Azzaz SA (1993) A laboratory simulation of degradation of Leinster granite by dry and wet deposition processes. Corrosion Science 34(3):511-524

Janvier-Badosa S (2012) Le carnet de santé d'un monument, application au château de Chambord, French Ph-D thesis, University of Orléans, 305 p.

Janvier-Badosa S, Beck K, Brunetaud X, Al-Mukhtar M (2013a) A historical study of Chambord castle: A basis for establishing the health record of the monument. International Journal of Architectural Heritage 7(3): 247-260

Janvier-Badosa S, Beck K, Brunetaud X, Al-Mukhtar M (2013b) The occurrence of gypsum in the scaling of stones at the castle of Chambord (France). Journal of Environmental Earth Sciences, DOI: 10.1007/s12665-013-2865-2

Janvier-Badosa S, Brunetaud X, Beck K, Al-Mukhtar M (2014) Kinetics of stone degradation of the Castle of Chambord France, Journal of Architectural Heritage. Accepted with minor revisions

Jeannette D (1992) Morphologie et nomenclature des altérations. La conservation de la pierre monumentale en France, ouvrage collectif sous la direction de Philippon J., Jeannette D., et R.A. Lefèvre, presses du CNRS, pp. 51-72

Kloppmann W, Bromblet P, Vallet JM, Vergès-Belmin V, Rolland O, Guerrot C, Gosselin C (2011) Building materials as intrinsic sources of sulphate: A hidden face of salt weathering of historical monuments investigated through multiisotope tracing (B, O, S). Science of the Total Environment 409(9):1658-1669

LIG'AIR. Monitoring air quality in the Central Region, France. http://www.ligair.fr/

NORMAL 13/83 (1983) Dosaggio dei sali solubili, CNR-ICR, Rome, Italy

Pauly JP (1990) Altération de la Pierre en œuvre en relation avec la climatologie et l'architecture. Simulation et produits de protection, French Ph-D thesis, Institut National Polytechnique de Loraine, 329 p.

Prick A (1996) Utilisation de la méthode dilatométrique dans l'étude expérimentale de l'altération de calcaires et de granites par du sulfate de calcium. Proceeding of the 1995 LCP Congress, Montreux, pp. 177-185

Rautureau M (2001) Tendre comme la pierre, ouvrage collectif sous la direction de Michel Rautureau. Ed. Conseil régional, Centre et Université d'Orléans

Rolland O (1999) Les châteaux de la Loire malades du plâtre?, CoRé, 6:49-53

Saiz-Jimenez C (1997) Biodeterioration vs. Biodegradation: The role of microorganisms in the removal of pollutants deposited on Historic Buildings. International Biodeterioration and Biodegradation 40(2-4):225-232

Sanjurjo Sánchez J, Romaní JRV, Alves C (2011) Deposition of particles on gypsum-rich coatings of historic buildings in urban and rural environments. Construction and Building Materials 25(2):813-822

Török Á, Licha T, Simon K, Siegesmund S (2011) Urban and rural limestone weathering; the contribution of dust to black crust formation. Environmental Earth Sciences 63(4):675-693 
Vallet JM, Gosselin C, Bromblet P, Rolland O, Vergès-Belmin V, and Kloppmann W (2006) Origin of salts in stone monument degradation using sulphur and oxygen isotopes: first results of the Bourges cathedral (France). Journal of Geochemical Exploration 88(1-3):358-362.

Van T-T, Beck K, Al-Mukhtar M (2007) Accelerated weathering tests on two highly porous limestones. Environmental Geology 52(2):283-292

Verges-Belmin V, Godin J, Brunjail C, Chéné G (2001) Etudes de cas, l'église Notre-Dame-la-Grande de Poitiers et la cathédrale Saint-Gatien de Tours, Géomécanique environnementale, risques naturels et patrimoine, sous la direction de Schrefler et Delage, éd. Hermès Science publication, pp. 307-329

Warscheid T, Braams J (2000) Biodeterioration of stone: a review. International Biodeterioration et Biodegradation 46:343-368 